\title{
Factors associated to the use of insecticide treated nets and intermittent preventive treatment for malaria control during pregnancy in Cameroon
}

\author{
Ngimuh Leonard $^{1 *}$ (D) Fokam Bertrand Eric ${ }^{2}$, Anchang-Kimbi K. Judith² and Wanji Samuel ${ }^{1,3}$
}

\begin{abstract}
Background: Malaria in pregnancy has been shown to cause both maternal and infant morbidity and mortality especially in sub Saharan Africa. The World Health Organization therefore recommends the use of insecticide treated nets (ITNs), intermittent preventive treatment (IPT) and effective management of clinical malaria. The main aim of this study was to assess the coverage of ITN and IPT among pregnant women and the factors associated with their use in the Buea Health District of Cameroon.

Methods: A cross sectional study was carried out from April to July 2014, in the Buea Health District which included 292 pregnant women attending antenatal care at clinics in the area. A structured questionnaire was use to obtain demographic data of participants and information on IPT and ITN use.

Results: The Overall coverage rate of IPT was $88.7 \%$ and $43.8 \%$ for ITN while the overall non usage rate for IPT and ITN was $11.3 \%$ and $17.5 \%$ respectively. Occupation, educational level, trimester and number of ANC were statistically significant to ITN use by bivariate analyses while being a student/ unemployed $(\mathrm{OR}=0.25,95 \% \mathrm{Cl}=0.07-0.95))$ was negatively associated to ITN use by multivariate analysis. For IPTp-SP, occupation of participants, educational level, trimester of pregnancy and number of ANC were statistically significantly by bivariate analyses while attending ANC just once $(\mathrm{OR}=0.006,95 \% \mathrm{Cl}=0.00-0.04)$ was negatively associated to IPTp-SP use by multivariate analyses.

Conclusion: This study identified that the use of IPT was fairly good, while ITN use was still low despite their free distribution. Therefore, frequent antenatal care visits and involvement of participants in a potential income generating venture (Business or earning a salary) will increase IPT and ITN usage.
\end{abstract}

Keywords: Usage, ITN, IPT and pregnancy

\section{Background}

Malaria infection during pregnancy is a serious public health problem which can result in maternal and new born morbidity and mortality, especially in sub Saharan Africa where about 30 millions pregnant women are at risk of the disease yearly [1]. In Cameroon, just like in other endemic areas, malaria has been shown to be a cause of maternal anaemia, intra-uterine growth retardation, low birth weight, stillbirths and abortions [2, 3].

\footnotetext{
* Correspondence: ngimleo@yahoo.com

${ }^{1}$ Department of Microbiology and Parasitology, University of Buea, Buea 63, Cameroon

Full list of author information is available at the end of the article
}

Pregnant women are more likely than non pregnant women to become infected with Plasmodium falciparum malaria and, once infected, there is a tendency toward increased severity of disease [4, 5]. The infection rate is higher among primigravidae than multidravid women [6].

The World Health Organization (WHO)'s recommendation for the control and prevention of malaria during pregnancy in areas of high to moderate malaria transmission in Africa is a package of intermittent preventive treatment (IPTp) with Sulfadoxine-Pyrimethamine (SP) and insecticide treated nets (ITNs) with effective management of clinical malaria and anaemia, which is 
commonly delivered through collaboration between malaria and reproductive-health programmes [5].

Studies show that the use of IPTp-SP for malaria in pregnancy in areas of high or seasonal transmission will result in lower placental infection rates, increase in both maternal haemoglobin levels and infant birth weight [7]. In addition, other studies in the mesoendemic area of the Thai-Burmese border and the Gambia [8,9] found reductions in maternal anaemia and low birth weight with the use of ITNs.

So far, very little work has been done on the factors associated to the use of IPTp-SP and ITN during pregnancy in Cameroon. This study therefore seeks to assess the coverage rate and factors associated to the use of ITN and IPTp-SP for the control of malaria during pregnancy.

\section{Methods}

\section{Study area}

The study was carried out in the Buea Health District (BHD) that comprises of both rural and urban communities. It has seven health areas with a total of 21 recognised health facilities of which Six were purposively selected: Mount Mary Hospital, Buea Road HC, Regional Hospital Buea, Solidarity Health Foundation, Molyko HC, Mile $16 \mathrm{IHC}$, to have a spatial distribution of the health facilities.

\section{Study design and population}

The study was a cross sectional hospital-based survey that contacted 410 pregnant women. However, 292 pregnant women met the inclusion criteria. That is being in their second or third trimester of pregnancy. There was no case of refusal. The survey was carried out from April to July 2014. The Cochran formula $\left(Z^{2} \mathbf{x} \mathbf{p}(\mathbf{1}-\mathbf{p}) / \mathbf{d} 2\right.$ Where $z=1.96$ for $95 \% C I ; p=I T N$ and IPT usage rate of $25 \%$ and $90 \%$ respectively; $d=$ precision) was used to estimate the minimum sample size assuming that, the proportion of pregnant women using ITN and IPT was $25 \%$ and $90 \%$ based on [10] and [11] respectively, with a $95 \%$ confidence interval and a $5 \%$ precision.

\section{Data collection}

A closed ended structured questionnaire was designed and administered in English. However, for all illiterate women, questions were translated and the participants were interviewed in "Pidgin" (Creole). The questionnaire sought to obtain demographic data and data on IPTp-SP and ITN use. Before the study started the questionnaire was pre-tested out of the study site and upon analysis,,the results were promising and questions in which participants had difficulties understanding were rephrased before the final study. Hospital records of participants were used to confirm IPTp-SP use and the dosage. The Roll Back Malaria(RBM) partnership indicator for ITN use which is

Table 1 Socio demographic characteristics of pregnant women attending ANC in the Buea Health District

\begin{tabular}{|c|c|c|c|c|c|c|}
\hline Characteristics & & Total enrolled & IPT users (\%) & IPT Non users (\%) & ITN users (\%) & ITN Non users (\%) \\
\hline Total & & 292 & $259(88.7)$ & $33(11.3)$ & $128(43.8)$ & $51(17.5)$ \\
\hline \multirow[t]{3}{*}{ Gravidity } & Primigravid & 97 & $94(36.3)$ & $3(9.1)$ & $27(21.1)$ & 18(35.3) \\
\hline & Secondigravid & 92 & $76(29.3)$ & $16(48.5)$ & $44(34.4)$ & $14(27.5)$ \\
\hline & Multigravid & 103 & $89(34.4)$ & $14(42.4)$ & $57(44.5)$ & 19(37.3) \\
\hline \multirow[t]{3}{*}{ Age } & $<20$ & 22 & $19(7.3)$ & $3(9.1)$ & $6(4.7)$ & $3(5.9)$ \\
\hline & $21-25$ & 98 & $92(35.5)$ & $6(18.2)$ & $29(22.7)$ & 19(37.3) \\
\hline & $>25$ & 172 & $148(57.1)$ & $24(72.4)$ & $93(72.6)$ & 29(56.9) \\
\hline \multirow[t]{4}{*}{ Occupation } & Students/unemployed & 92 & $88(34)$ & $4(12.1)$ & 19(14.8) & $26(51.0)$ \\
\hline & Business & 90 & $79(30.5)$ & $11(33.3)$ & 43(33.6) & $12(23.5)$ \\
\hline & Civil servants & 58 & $50(19.3)$ & $8(24.2)$ & $34(26.6)$ & $7(13.7)$ \\
\hline & House wife/ farmers & 52 & $42(16.2)$ & 10(30.3) & $32(25)$ & $6(11.8)$ \\
\hline \multirow[t]{3}{*}{ Number of ANC Attendance } & First & 27 & $5(1.9)$ & $22(66.7)$ & 24(18.8) & $1(2.0)$ \\
\hline & Second & 88 & $81(31.3)$ & $7(21.2)$ & $36(28.1)$ & $12(23.5)$ \\
\hline & Third or more & 177 & 173(66.8) & $4(12.1)$ & $68(53.1)$ & $38(74.5)$ \\
\hline \multirow[t]{3}{*}{ Education } & Primary & 68 & $56(21.6)$ & $12(36.4)$ & $36(28.1)$ & 10(19.6) \\
\hline & Secondary/high & 126 & 108(41.7) & $18(54.5)$ & $62(48.4)$ & 19(37.3) \\
\hline & Tertiary & 98 & $95(36.7)$ & $3(9.1)$ & $30(23.4)$ & $22(43.1)$ \\
\hline \multirow[t]{2}{*}{ Trimester } & Second & 150 & $120(46.3)$ & 30(90.9) & $73(57)$ & 19(37.3) \\
\hline & Third & 142 & 139(53.7) & $3(9.1)$ & $55(43)$ & $32(62.7)$ \\
\hline
\end{tabular}


based on the proportion of pregnant women who slept under an ITN the previous night [12] was equally used to determine ITN use. The term ITN in this study was referred to nets that had been treated with insecticide and needed ongoing treatment. Or long lasting insecticide nets which are currently the most frequently distributed types of net in Africa [12]. The term free distribution net in this study refers to the door to door distribution as well as free nets received from the hospital. A sample size of 288 or 139 had been estimated to provide the desired outcome at $5 \%$ precision, $95 \%$ confidence level and an estimated usage rate for ITN of $25 \%$ [10] and $90 \%$ [11] for IPT.

\section{Ethical considerations}

The study was approved by the Institutional Review Board of the Faculty of Health Sciences of the University of Buea. And an administrative authorisation was obtained from the Regional Delegation of Public Health, South West region and the District Medical Officer of Buea. Consent was sought from the different health facilities selected for the study. Informed consent was obtained from the women prior to their interview at the clinic.

\section{Data analysis}

A template of the questionnaire was prepared using Epi Info version 3.4.3 statistical software and the data entered and subsequently exported to the Statistical Package for the Social Sciences SPSS version 20 (SPSS, Inc., Chicago, IL, USA) and analyzed. A descriptive statistical analysis was carried out on the use of ITN and IPT. Differences in proportions were analyzed using Chi square $\left(\chi^{2}\right)$ tests. Multivariate analysis was done for all significant values obtained from bivariate analysis to get the best-fit model using unconditional multiple logistic regression. A $P$-value $<0.05$ was considered a statistically significant association.

\section{Results}

The majority of pregnant women in this survey were greater than 25 years, and the ages ranged from 18 to 48 years with a mean age of $26.73 \pm 4.681$. More than half of the women $(60.6 \%)$ were attending ANC for the third time or more; more than two thirds were enrolled or had attained secondary/high school or tertiary level of education, while $22.9 \%$ had the primary level of education (Table 1). The overall use of ITN was $43.8 \%$ and of IPTp-SP was $88.7 \%$ while the overall non usage rate for

Table 2 Factors associated to ITN use in the Control of malaria in pregnancy using Bivariate and Multivariate analysis

\begin{tabular}{|c|c|c|c|c|c|c|}
\hline \multirow[t]{2}{*}{ Factors } & & \multirow[t]{2}{*}{ ITN use (\%) } & \multirow{2}{*}{$\begin{array}{l}\text { ITN Non } \\
\text { users (\%) }\end{array}$} & \multirow[t]{2}{*}{ Significance } & \multicolumn{2}{|c|}{ Multivariate analysis } \\
\hline & & & & & OR $(95 \% \mathrm{Cl})$ & $P$-value \\
\hline \multirow[t]{3}{*}{ Gravidity } & Primigravid & $27(21.1)$ & 18(35.3) & $x 2=3.92$ & NA & \\
\hline & Secundigravid & 44(34.4) & $14(27.5)$ & $P=0.141$ & NA & \\
\hline & muitigravid & $57(44.5)$ & 19(37.3) & & NA & \\
\hline \multirow[t]{3}{*}{ Age } & $<20$ & $6(4.7)$ & $3(5.9)$ & $x 2=3.92$ & NA & \\
\hline & $21-25$ & $29(22.7)$ & 19(37.3) & $P=0.141$ & NA & \\
\hline & $>25$ & $93(72.6)$ & $29(56.9)$ & & NA & \\
\hline \multirow[t]{4}{*}{ Occupation } & Students/unemployed & 19(14.8) & $26(51.0)$ & $x 2=25.779$ & $0.25(0.07-0.95)$ & 0.042 \\
\hline & Business & 43(33.6) & $12(23.5)$ & $P=0.001$ & 0.65(0.18-2.35) & 0.511 \\
\hline & Civil servants & $34(26.6)$ & $7(13.7)$ & & $1.39(0.33-5.75)$ & 0.654 \\
\hline & House wife/ farmers & $32(25)$ & 6(11.8) & & REF & \\
\hline \multirow[t]{3}{*}{ Educational level } & Primary & 56(21.6) & 10(19.6) & $x^{2}=6.909$ & $2.4(0.57-10.18)$ & 0.234 \\
\hline & Secondary/high & 108(41.7) & 19(37.3) & $P=0.032$ & $2.11(0.77-5.77)$ & 0.147 \\
\hline & Tertiary & 95(36.7) & $22(43.1)$ & & REF & \\
\hline \multirow[t]{2}{*}{ Trimester } & Second & $73(57)$ & 19(37.3) & $x^{2}=5.710$ & $1.64(0.63-4.27)$ & 0.312 \\
\hline & Third & $55(43)$ & $32(62.7)$ & $P=0.017$ & REF & \\
\hline \multirow[t]{3}{*}{ Source of ITN } & Hospital & 50(39.1) & 18(41.9) & $x 2=11.912$ & 7.45(0.67-83.22) & 0.103 \\
\hline & Free distribution & $77(60.2)$ & $20(46.5)$ & $P=0.003$ & 8.06(0.75-87.04) & 0.09 \\
\hline & Bought & $1(0.8)$ & $5(11.6)$ & & REF & \\
\hline \multirow[t]{3}{*}{ Number of ANC visits } & One & 24(18.8) & $1(2.0)$ & $x 2=10.464$ & 4.23(0.46-39.19) & 0.204 \\
\hline & Twice & $36(28.1)$ & $12(23.5)$ & $P=0.005$ & $1.46(0.53-4.01)$ & 0.461 \\
\hline & Thrice or more & $68(53.1)$ & $38(74.5)$ & & REF & \\
\hline
\end{tabular}


IPT and ITN was $11.3 \%$ and $17.5 \%$ respectively. The use of both ITN and IPTp-SP was highest among multigravid women (42.3\%); women in their third trimester (53.6\%), women aged 26 years and above $(72.2 \%)$ and women who had three or more ANC attendance (67\%). The non usage of ITN and IPT was highest among women in their second trimester and first ANC attendance. A detailed comparison is found in table.

\section{Factors associated to ITN use}

Bivariate analyses for factors associated with ITN use showed that the following factors were statistically significant at $P<0.05$ : occupation, trimester of pregnancy, source of net, number of ANC visits (Table 2).

Again, using multivariate analyses to obtain the final best-fit model, only one factor (occupation of participants) was found to be independently associated with ITN use, with being a student/unemployed person negatively associated to IPT use.

\section{Factors associated to IPTp-SP use}

Bivariate analyses for factors associated with IPTp-SP use showed that the following factors were statistically significant at $P<0.05$ : gravidity, occupation, educational level, trimester of pregnancy, number of ANC visits. Again, using multivariate analyses to obtain the final best-fit model, only one factor that is ANC attendance, was found to be independently associated with IPTp-SP use, with those visiting the clinics just once being negatively associated to IPTp-SP use (Table 3).

\section{Discussion}

This study assessed factors affecting the uptake of IPTpSP and use of ITN among pregnant women in the BHD. The overall usage rate obtained for ITN was $43.8 \%$, which is half of that reported in Sudan [13], but similar to that reported in Tanzania [14]. However, it was less than the target for the Abuja Declaration which was set at a target of $60 \%$ ITN coverage. The usage rate of IPTp-SP was $88.7 \%$ which is above the $80 \%$ set by Roll Back Malaria Partnership for 2010, but less than the ambitious $100 \%$ coverage set for 2015 by the same organization. The highest proportion of both ITN and IPTp-SP users were in the $>25$ year-old group,,women who were currently enrolled or had obtained the secondary or high school level of education that is multigravid women and those that had attended ANC three or more times. This might be because multigravid women already know the dangers of malaria in pregnancy. Also those with more ANC attendance had high chances of receiving more lectures on the importance of ITN and IPTpSP and hence increasing their usage rate. Primigravid women were more likely to use IPTp-SP than ITN which is similar to findings made in a meta analysis [15].

The lone independent factor associated to ITPp-SP use was number of ANC attended, which is similar to

Table 3 Factors associated to IPTp use for malaria control in pregnancy using bivariate and multivariate analysis

\begin{tabular}{|c|c|c|c|c|c|c|}
\hline \multirow[t]{2}{*}{ Factors } & & \multirow[t]{2}{*}{ IPT use (\%) } & \multirow[t]{2}{*}{ IPT Non users (\%) } & \multirow[t]{2}{*}{ Significant } & \multicolumn{2}{|c|}{ Multivariate analysis } \\
\hline & & & & & OR (95\% Cl) & p-value \\
\hline \multirow[t]{3}{*}{ Gravidity } & Primigravid & $94(36.3)$ & $3(9.1)$ & $x 2=10.463$ & $5.04(0.69-37.10)$ & 0.112 \\
\hline & Secundigravid & $76(29.3)$ & $16(48.5)$ & $P=0.005$ & $0.41(0.11-1.56)$ & 0.190 \\
\hline & Multigravid & $89(34.4)$ & $14(42.4)$ & & REF & \\
\hline \multirow[t]{3}{*}{ Age } & $<20$ & $19(7.3)$ & $3(9.1)$ & $x^{2}=3.949$ & NA & \\
\hline & $21-25$ & $92(35.5)$ & $6(18.2)$ & $P=0.139$ & NA & \\
\hline & $>25$ & $148(57.1)$ & $24(72.4)$ & & NA & \\
\hline \multirow[t]{4}{*}{ Occupation } & Students/unemployed & $88(34)$ & $4(12.1)$ & $x^{2}=8.135$ & $1.64(0.28-9.67)$ & 0.586 \\
\hline & Business & $79(30.5)$ & $11(33.3)$ & $P=0.043$ & $4.31(0.85-21.86)$ & 0.079 \\
\hline & Civil servants & $50(19.3)$ & $8(24.2)$ & & $0.51(0.07-3.92)$ & 0.520 \\
\hline & House wife/farmers & $42(16.2)$ & 10(30.3) & & REF & \\
\hline \multirow[t]{3}{*}{ Educational level } & Primary & 49(19.4) & 12(36.4) & $x^{2}=11.749$ & $0.23(0.02-2.14)$ & 0.195 \\
\hline & Secondary/high & 108(42.9) & $18(54.5)$ & $P=0.003$ & $0.26(0.05-1.46)$ & 0.126 \\
\hline & Tertiary & $95(37.7)$ & $3(9.1)$ & & REF & \\
\hline \multirow[t]{2}{*}{ Trimester of pregnancy } & Second & $120(46.3)$ & 30(90.9) & $x 2=23.283$ & $0.25(0.06-1.13)$ & 0.071 \\
\hline & Third & 139(53.7) & $3(9.1)$ & $P=0.000$ & REF & \\
\hline \multirow[t]{3}{*}{ Number of ANC visits } & One & $5(1.9)$ & $22(66.7)$ & $X 2=148.08$ & $0.006(0.00-0.04)$ & 0.001 \\
\hline & Twice & $81(31.3)$ & $7(21.2)$ & $P=0.000$ & $0.39(0.10-1.56)$ & 0.181 \\
\hline & Thrice or more & $173(66.8)$ & $4(12.1)$ & & REF & \\
\hline
\end{tabular}


findings made in Sudan [13]. This shows that the more the women go for ANC, the more knowledge they acquire and the more likely they are to accept and receive IPTp-SP. This therefore explains why those who attended ANC just once were negatively associated to IPTp-SP use. This finding is different from that reported in a study in Tanzania [16] where number of ANC attended had no effect on IPTp use.

Furthermore, occupation was the only independently associated factor to ITN use with being a student/ unemployed negatively associated to ITN use.

Information or recall bias may have occurred during the study because the data on ITN use was based on interview.

No causal inferences may be drawn from these findings because of the weak nature of cross-sectional studies.

\section{Conclusion}

This study identified that the use of IPT was fairly good while ITN use is still low despite their free distribution. However, the use of IPTp and ITN are independently affected by factors such as number of ANC attended and occupation of participant respectively. Effective public health education on the use of ITNs should be reinforced in addition to giving them out for free, to enhance accessibility to and use of IPT and ITN. It might be productive for public health authorities and actors to undertake mass awareness campaigns to educate mothers on the importance of regular ANC visits and IPT use targeting especially people with low levels of education, pregnant teenagers, students and the unemployed.

\section{Competing interests}

The authors declare that they have no competing interests.

\section{Authors' contributions}

$\mathrm{NL}$ : Conception and design of study, data collection, analysis, interpretation and manuscript preparation and pretested the questionnaire. EF: overseeing of study design, data collection, analysis, manuscript preparation. SW and JA-K: preparation and critical reading of the manuscript for important and intellectual content. All authors read and approved the contents of the manuscript.

\section{Acknowledgements}

We thank the entire staff of Mount Mary Hospital Buea, Regional Hospital Annex, Buea; Integrated Health Centre Mile 16, Buea Road Integrated Health Centre, Molyko Integrated Health Centre, Solidarity Health Foundation Molyko, and Research Foundation in Tropical Diseases and Environment for their endless support during this work and the mothers who volunteered to participate in this study.

\section{Author details}

'Department of Microbiology and Parasitology, University of Buea, Buea 63, Cameroon. ${ }^{2}$ Department of Zoology and Animal Physiology, University of Buea, Buea 63, Cameroon. ${ }^{3}$ Research Foundation in Tropical Diseases and Environment, P.O.Box 474, Buea, Cameroon.

Received: 26 August 2015 Accepted: 11 January 2016 Published online: 01 February 2016

\section{References}

1. Dellicour S, Tatem AJ, Guerra CA, Snow RW, ter Kuile FO. Quantifying the number of pregnancies at risk of malaria in 2007: a demographic study. PLOS ONE. 2010;7:e1000221.

2. Anchang-Kimbi JK, Achidi EA, Nkegoum B, Sverremark-Ekstrom E, TroyeBlomberg M. Diagnostic comparison of malaria infection in peripheral blood, placental blood and placental biopsies in Cameroonian parturient women. Malar J. 2009:8:126.

3. Adebami OJ, Owa JA, Oyedeji GA, Oyelami OA, Omoniyi-Esan GO. Associations between placental and cord blood malaria infection and foetal malnutrition in an area of malaria holoendemicity. Am J Trop Med Hyg. 2007;77(2):209-13.

4. Parise ME, Ayisi JG, Nahlen BL, Schultz LJ, Roberts JM, Misore A, et al. Efficacy of sulfadoxine-pyrimethamine for prevention of placental malaria in an area of Kenya with a high prevalence of malaria and human immunodeficiency virus infection. Am J Trop Med Hyg. 1998;59:813-22.

5. WHO. A strategic framework for malaria prevention and control during pregnancy in the African region. AFR/MAL/04/01. Brazzaville: WHO Regional Office for Africa; 2004

6. Brabin B. An assessment of low-birth weight risk in primiparae as an indicator of malaria control in pregnancy. Int J Epidemiol. 1991;20:276-83.

7. Shulman CE, Dorman EK, Cutts F, Kawuondo K, Bulmer JN, Peshu N, et al. Intermittent sulphadoxine-pyrimethamine to prevent severe anaemia secondary to malaria in pregnancy: a randomised placebo-controlledtrial. Lancet. 1999:353:632-6.

8. Dolan G, ter Kuile FO, Jacoutot V, White NJ, Luxemburger C, Malankirii L, et al. Bed nets for the prevention of malaria and anaemia in pregnancy. Trans R Soc Trop Med Hyg. 1993;87:620-6.

9. D'Alessandro U, Langerock P, Bennett S, Francis N, Cham K, Greenwood BM. The impact of a national impregnated bed net programme on the outcome of pregnancy in primigravidae in The Gambia. Trans R Soc Trop Med Hyg. 1996:90:487-92

10. Pettifor A, Taylor E, Nku D, Duvall S, Tabala M, Meshnick S, et al. Bed net ownership, use andperceptions among women seeking antenatal care in Kinshasa, Democratic Republic of the Congo (DRC): opportunities for improved maternal and child health. BMC Public Health. 2008;8:331.

11. Anchang-Kimbi JK, Achidi EA, Apinjoh TO, Mugri RN, Chi HF, Tata RB, et al. Antenatal care visit attendance, intermittent preventive treatment during pregnancy (IPTp) and malaria parasitaemia at delivery. Malar J. 2014;13:163.

12. World Health Organisation. World malaria report. 2011. www.who.int.

13. Napoleon PR, Anyangu SA, Omolocanc J, Ongus RJ. Preventing malaria during pregnancy: factors determining the use of insecticide-treated bednets and intermittent preventive therapy in Juba. Southern Sudan Med J. 2011:4:2.

14. Marchant T, Schellenberg JA, Edgar T, Nathan R, Abdulla S, Mukasa O, Mponda $\mathrm{H}$, Lengeler $\mathrm{C}$. Socially marketed insecticide-treated nets improve malaria and anaemia in pregnancy in southern Tanzania. Trop Med Int Health. 2002;7(2):149-58.

15. Hill J, Dellicour S, Bruce J, Ouma P, Smedley J, Otieno P, et al. Effectiveness of antenatal clinics to deliver intermittent preventive treatment and insecticide treated nets for the control of malaria in pregnancy in Kenya. PLOS ONE. 2013;8(6):e64913.

16. Exavery A, Mbaruku G, Mbuyita S, Makemba A, Kinyonge PI, Kweka H. Factors affecting uptake of optimal doses of sulphadoxine-pyrimethamine for intermittent preventive treatment of malaria in pregnancy in six districts of Tanzania. Malar J. 2014:13:22. doi:10.1186/1475-2875-13-22

Submit your next manuscript to BioMed Central and we will help you at every step:

- We accept pre-submission inquiries

- Our selector tool helps you to find the most relevant journal

- We provide round the clock customer support

- Convenient online submission

- Thorough peer review

- Inclusion in PubMed and all major indexing services

- Maximum visibility for your research 